University of Nebraska - Lincoln

DigitalCommons@University of Nebraska - Lincoln

Agronomy \& Horticulture -- Faculty Publications

Agronomy and Horticulture Department

7-1991

\title{
Seed Weight Influence on Seedling Hydrocyanic Acid Potential in Sorghum
}

\author{
J. F.S. Lamb \\ University of Nebraska-Lincoln \\ Francis A. Haskins \\ University of Nebraska-Lincoln, fhaskins@neb.rr.com \\ Herman J. Gorz \\ United States Department of Agriculture \\ K. P. Vogel \\ United States Department of Agriculture, kvogel1@unl.edu
}

Follow this and additional works at: https://digitalcommons.unl.edu/agronomyfacpub

Part of the Plant Sciences Commons

Lamb, J. F.S.; Haskins, Francis A.; Gorz, Herman J.; and Vogel, K. P., "Seed Weight Influence on Seedling Hydrocyanic Acid Potential in Sorghum" (1991). Agronomy \& Horticulture -- Faculty Publications. 249. https://digitalcommons.unl.edu/agronomyfacpub/249

This Article is brought to you for free and open access by the Agronomy and Horticulture Department at DigitalCommons@University of Nebraska - Lincoln. It has been accepted for inclusion in Agronomy \& Horticulture -Faculty Publications by an authorized administrator of DigitalCommons@University of Nebraska - Lincoln. 


\title{
Seed Weight Influence on Seedling Hydrocyanic Acid Potential in Sorghum
}

\author{
J. F. S. Lamb, F. A. Haskins, H. J. Gorz, and K. P. Vogel*
}

\begin{abstract}
Grain sorghum [Sorghum bicolor (L.) Moench] typically produces larger seeds than sudangrass [S. bicolor, formerly $S$. sudanense (Piper) Stapf]; and grain sorghum seedlings are higher in hydrocyanic acid potential (HCN-p) than sudangrass seedlings. Previous studies have shown a seed-parent effect on seed weight and HCN-p in reciprocal $F_{1}$ hybrids of sorghum $X$ sudangrass. This study was conducted to determine whether the seed-parent effect on HCN-p could be attributed primarily to the difference in seed size between reciprocal sorghum $X$ sudangrass hybrids. Large and small seeds of lowHCN-p sudangrass, high-HCN-p sorghum, and their reciprocal hybrids, were visually selected, individually weighed, and planted in growth chambers. Height, fresh weight, and HCN-p of the resulting 7-d-old shoots were measured. On average, the selected large seeds weighed $\approx 1.6$ times as much as the small seeds. Shoots from the large seeds were $\approx 1.2$ times as tall and 1.4 times as heavy as those from small seeds, and they contained $\approx 1.3$ times as much HCN per shoot as did shoots from small seeds. However, the HCN-p (mg $\mathrm{kg}^{-1}$ fresh wt.) of the shoots from large seeds was only slightly greater than that of shoots from small seeds ( 709 and 701 for first leaves of shoots, and 278 and 267 for shoot remainders from large and small seeds, respectively). Shoots from 5-d-old light-grown and etiolated seedlings also failed to show appreciable differences in HCN$p$ due to seed size. It was concluded that the seed-parent effect on shoot HCN-p in crosses of sorghum and sudangrass was not caused primarily by the seed-parent effect on seed weight.
\end{abstract}

$I^{N}$ A RECENT study of the inheritance of seedling hydrocyanic acid potential in crosses between highHCN-p sorghum and low-HCN-p sudangrass, results indicated a maternal or seed-parent effect for seed weight and seedling $H C N-p$ in the $F_{1}$ and backcross generations (Lamb et al., 1987); however, no evidence of this reciprocal effect was found in the $F_{2}$, suggesting that cytoplasmic inheritance is not involved. High, positive correlations $(P \leq 0.01)$ between seed weight and seedling HCN-p were found for all entries taken together $\left(r=0.85^{* *}\right.$; significant at $\left.p \leq 0.01\right)$, for all parental lines $\left(r=0.82^{* *}\right)$, for all $\mathrm{F}_{1}$ populations $(r$ $\left.=0.69^{* *}\right)$, and for all backcross populations $(r=$

J.F.S. Lamb and F.A. Haskins, Dep. of Agronomy; H.J. Gorz and K.P. Vogel, USDA-ARS and Dep. of Agronomy, Nebraska Agric Res. Div., Lincoln, NE 68583. Published as Paper no. 9219, Journal Series, Nebraska Agric. Res. Div. Research was conducted under Project no. 12-114. Received 9 July $1990 .{ }^{*}$ Corresponding author.

Published in Crop Sci. 31:1014-1016 (1991).

Abbreviation: $\mathrm{HCN}-\mathrm{p}$, hydrocyanic acid potential
$0.85^{* *}$ ) (Lamb et al., 1987); however, correlations between seed weight and seedling $\mathrm{HCN}$-p for individual entries, the pooled $F_{2}$ 's, or within types of seed parent in the $F_{1}$ or backcross generations were generally nonsignificant. Thus, seed weight per se appeared not to have a large effect on seedling $\mathrm{HCN}$-p.

The foregoing report (Lamb et al., 1987) dealt only with seed weight and seedling $\mathrm{HCN}$-p, and values for seed weight were means calculated from the number and total weight of seeds planted in each replicate. Weights of individual seeds giving rise to the sampled seedlings were not known. The primary objective of the present study was to investigate in greater detail the possible effect of seed weight on seedling HCN-p and other seedling traits within sorghum and sudangrass parental lines and reciprocal $F_{1}$ sorghum $X$ sudangrass hybrids. Backcross and $F_{2}$ populations were excluded because the genetic diversity in such populations was undesirable for this study. Individual seeds were weighed, and measurements were made of the fresh weight, height, and HCN-p of individual shoots arising from identified seeds.

A brief study also was made that used seedlings grown in water-saturated vermiculite. The rationale for this study was that in the absence of exogenous nutrients, seed-size dependent differences in seedling traits might be especially distinct.

\section{MATERIALS AND METHODS \\ Seven-Day, Light-Grown Seedlings}

Two low-HCN-p sudangrass lines, 1901 and 1904; and four high-HCN-p sorghum lines, ACK 60, BCK60, ARedlan, and BRedlan, were used as parental lines in this study. Reciprocal sorghum $\times$ sudangrass hybrids included the following: $1901 \times$ BCK60, ACK $60 \times 1901,1901 \times$ BRedlan, ARedlan $\times 1901,1904 \times$ BCK60, ACK60 × 1904, 1904 $\times$ BRedlan, and ARedlan $\times 1904$. Further descriptions of the parental lines and the crosses used to produce the $F_{1}$ hybrids are given by Lamb et al. (1987).

Large and small seeds of each entry were selected visually. For each replicate, 10 large and 10 small seeds of each entry were individually weighed. The 10 large seeds of a given entry were planted in identified positions in a single row in a small plastic pan, and 10 small seeds of the same entry were planted in an adjacent row. The 14 entries (14 pairs of rows) were randomly arranged in each replicate of the experiment, and eight separate plantings provided a total of eight replicates. Seedlings were grown in a soil mixture under continuous cool-white fluorescent light $\left(\approx 150 \mu \mathrm{mol} \mathrm{m}^{-2}\right.$ $\mathrm{s}^{-1}$ ) at $27^{\circ} \mathrm{C}$, essentially as described by Gorz et al. (1977). 
At $7 \mathrm{~d}$ after planting, three representative seedlings were chosen for assay from each of the 28 rows. Seedling height was measured, and the first leaf of each sampled seedling was then harvested separately from the shoot remainder, which was excised at the soil surface. Both shoot portions were weighed, extracted, and assayed as described by Gorz et al. (1977).

Analysis of variance for a randomized complete-block design was used for all traits measured. The error cross products and sums of squares matrix from this analysis were used to calculate partial correlation coefficients for seedlings within entries for all traits. Phenotypic correlations between traits across all entries were determined by using mean squares and mean products from the analyses of variance and covariance as described by Falconer (1981).

\section{Five-Day, Light- and Dark-Grown Seedlings}

Parental lines 1904 and BRedlan and the crosses $1904 \times$ BRedlan and ARedlan $\times 1904$ were used. Two sets of 20 small and 20 large seeds (individually weighed) of each parent and $F_{1}$ hybrid were planted in water-saturated vermiculite. One set was placed in continuous light at $27^{\circ} \mathrm{C}$ as described above, and the other in a light-excluding container in the same growth chamber. At $5 \mathrm{~d}$, seedlings were harvested and each was separated into shoot, root, and seed remnant. The portions were bulked within entry, light treatment, seed size, and type of portion. The bulked samples were weighed, extracted, and assayed for HCN-p by the spectrophotometric procedure of Gorz et al. (1977). Also, the absorbance spectrum of each base-diluted extract was scanned from 400 to $220 \mathrm{~nm}$.

\section{RESULTS AND DISCUSSION}

\section{Seven-Day, Light-Grown Seedlings}

Results were similar within each of the parental types and also within each type of $F_{1}$ hybrid; therefore, data were pooled within each of these four types of entry as shown in Table 1. Means for both first-leaf and shoot-remainder HCN-p showed the same sort of seed-parent influence as that previously observed by Lamb et al. (1987); that is, values for sorghum $\times$ sudangrass hybrids were higher than those for sudangrass $X$ sorghum hybrids. This was true of seedlings from both small and large seeds. Results were consistent within entries and across all entries for seed size differences (Table 1). Seedlings from large seeds were significantly taller and had significantly greater first-leaf and shoot-remainder weights than those from small seeds. There were no significant differences due to seed size within entries or across all entries for firstleaf $\mathrm{HCN}-\mathrm{p}$ or shoot-remainder $\mathrm{HCN}$-p, except for shoot-remainder $\mathrm{HCN}$-p of sudangrass $\times$ sorghum seedlings, and that difference was small $(12 \mathrm{mg} \mathrm{kg}$ fresh wt.). Hydrocyanic acid per shoot is a product of shoot weight and HCN-p, and the apparent effect of seed size on $\mathrm{HCN}$ per shoot was primarily a result of the effect on shoot weight rather than on HCN-p.

Within-entry and overall phenotypic correlations for all pairs of traits are shown in Table 2 . The withinentry values indicated significant association of seed

Table 1. Influence of seed size on various traits of 7-d-old light-grown seedlings of low-HCN-p (hydrocyanic acid-potential) sudangrasses, high-HCN-p sorghums, and their reciprocal $F_{1}$ hybrids. $\dagger$

\begin{tabular}{|c|c|c|c|c|c|c|}
\hline Trait & Seed size & $\begin{array}{l}\text { Sudangrass } \\
\text { parents }\end{array}$ & $\begin{array}{c}\text { Sorghum } \\
\text { parents }\end{array}$ & $\begin{array}{c}\text { Sudangrass } \\
\text { sorghum }\end{array}$ & $\begin{array}{c}\text { Sorghum } \times \\
\text { sudangrass }\end{array}$ & Over all entries \\
\hline Seed weight, & Small & $7.1 \pm 0.1^{* *}$ & $18.9 \pm 0.4^{* *}$ & $8.2 \pm 0.1^{* *}$ & $17.7 \pm 0.3^{* *}$ & $13.8 \pm 0.3^{* *}$ \\
\hline mg seed ${ }^{-1}$ & Large & $12.5 \pm 0.1$ & $27.6 \pm 0.5$ & $14.7 \pm 0.1$ & $27.9 \pm 0.2$ & $21.8 \pm 0.4$ \\
\hline Seedling height, & Small & $111 \pm 2^{* *}$ & $87 \pm 1^{* *}$ & $113 \pm 1^{* *}$ & $134 \pm 2^{* *}$ & $112 \pm 1^{* *}$ \\
\hline $\mathbf{m m}$ & Large & $133 \pm 4$ & $97 \pm 1$ & $141 \pm 1$ & $150 \pm 2$ & $130 \pm 1$ \\
\hline First-leaf weight, & Small & $13.5 \pm 0.4^{* *}$ & $12.5 \pm 0.3^{* *}$ & $14.8 \pm 0.2^{* *}$ & $16.5 \pm 0.3^{* *}$ & $14.5 \pm 0.2^{* *}$ \\
\hline mg fr wt. & Large & $16.6 \pm 0.5$ & $13.6 \pm 0.2$ & $19.0 \pm 0.3$ & $19.2 \pm 0.3$ & $17.2 \pm 0.2$ \\
\hline First-leaf HCN-p, & Small & $221 \pm 10$ & $1194 \pm 24$ & $487 \pm 9$ & $674 \pm 18$ & $701 \pm 21$ \\
\hline$m g$ kg$^{-1}$ fr wt. & Large & $226 \pm 10$ & $1167 \pm 22$ & $505 \pm 10$ & $695 \pm 13$ & $709 \pm 19$ \\
\hline Shoot-remainder weight, & Small & $38.4 \pm 1.4^{* *}$ & $66.5 \pm 2.3^{* *}$ & $50.7 \pm 1.1^{* *}$ & $93.0 \pm 2.3^{* *}$ & $65.5 \pm 1.5^{* *}$ \\
\hline mg fr wt. & Large & $56.2 \pm 2.7$ & $83.0 \pm 2.3$ & $92.1 \pm 1.7$ & $131.1 \pm 2.5$ & $95.5 \pm 1.8$ \\
\hline Shoot-remainder HCN-p, & Small & $94 \pm 4$ & $516 \pm 10$ & $147 \pm 3^{*}$ & $229 \pm 7$ & $267 \pm 10$ \\
\hline$m g \mathbf{~ k g}^{-1}$ fr $\mathbf{w t}$ & Large & $101 \pm 4$ & $518 \pm 10$ & $159 \pm 4$ & $244 \pm 6$ & $278 \pm 9$ \\
\hline Total shoot weight, & Small & $51.9 \pm 1.7^{* *}$ & $79.0 \pm 2.5^{* *}$ & $65.4 \pm 1.2^{* *}$ & $109.4 \pm 2.6^{* *}$ & $80.0 \pm 1.6^{* *}$ \\
\hline mg fr wt. & Large & $72.7 \pm 3.1$ & $96.6 \pm 2.4$ & $111.1 \pm 1.9$ & $150.3 \pm 2.7$ & $112.7 \pm 1.9$ \\
\hline Total HCN shoot ${ }^{-1}$, & Small & $6.6 \pm 0.3^{* *}$ & $49.3 \pm 1.6^{* *}$ & $14.6 \pm 0.3^{* *}$ & $31.8 \pm 0.9^{* *}$ & $28.2 \pm 1.0^{* *}$ \\
\hline$\mu \mathrm{g}$ & Large & $9.5 \pm 0.5$ & $59.0 \pm 1.7$ & $24.0 \pm 0.5$ & $44.5 \pm 0.8$ & $37.8 \pm 1.1$ \\
\hline
\end{tabular}

*,** Differences between the two seed sizes are significant at the 0.05 and 0.01 levels of probability, respectively, as shown by a $t$-test.

$\dagger$ Means and standard errors are shown; $n=48$ for sudangrass parents, 336 for all entries combined, and 96 for the other entries. Fresh weight is denoted by fr wt.

Table 2. Partial correlation coefficients for seedlings of sudangrass and sorghum and their reciprocal $F_{1}$ hybrids within entries (above diagonal) and overall phenotypic correlations for pairs of traits of all entries (below diagonal).

\begin{tabular}{|c|c|c|c|c|c|c|c|c|}
\hline & $\begin{array}{c}\text { Seed } \\
\text { weight }\end{array}$ & $\begin{array}{c}\text { Seedling } \\
\text { height }\end{array}$ & $\begin{array}{c}\text { First-leaf } \\
\text { weight }\end{array}$ & $\begin{array}{l}\text { First-leaf } \\
\text { HCN-p } \dagger\end{array}$ & $\begin{array}{c}\text { Shoot-remainder } \\
\text { weight }\end{array}$ & $\begin{array}{c}\text { Shoot-remainder } \\
\text { HCN-p }\end{array}$ & $\begin{array}{c}\text { Total shoot } \\
\text { weight }\end{array}$ & $\begin{array}{c}\text { Total HCN } \\
\text { per shoot }\end{array}$ \\
\hline Seed weight & - & $0.56^{* *}$ & $0.47^{* *}$ & 0.06 & $0.70^{* *}$ & $0.12^{* *}$ & $0.69^{* *}$ & $0.57^{* *}$ \\
\hline Seedling height & -0.18 & - & $0.76 * *$ & -0.04 & $0.81^{* *}$ & -0.08 & $0.82^{* *}$ & $0.51 * *$ \\
\hline First-leaf weight & -0.15 & $0.89 * *$ & - & $-0.17^{* *}$ & $0.77^{* *}$ & $0.13^{* *}$ & $0.81^{* *}$ & $0.53^{* *}$ \\
\hline First-leaf $\mathrm{HCN}-\mathrm{p}$ & $0.73^{* *}$ & $-0.67^{* *}$ & -0.50 & - & 0.00 & $0.70^{* *}$ & -0.02 & $0.40^{* *}$ \\
\hline Shoot-remainder weight & $0.69^{* *}$ & 0.52 & $0.53^{*}$ & 0.24 & - & 0.00 & $0.99^{* *}$ & $0.76^{* *}$ \\
\hline Shoot-remainder HCN-p & $0.70^{* *}$ & $-0.76^{* *}$ & $-0.59^{*}$ & $0.98^{* *}$ & 0.12 & - & -0.01 & $0.49^{* *}$ \\
\hline Total shoot weight & $0.64^{*}$ & $0.58 *$ & $0.60^{*}$ & 0.18 & $0.99^{* *}$ & 0.06 & - & $0.75^{* *}$ \\
\hline Total HCN shoot ${ }^{-1}$ & $0.88^{* *}$ & -0.47 & $-\mathbf{0 . 3 2}$ & $0.95^{* *}$ & 0.48 & $0.93^{* *}$ & 0.42 & - \\
\hline
\end{tabular}

*** Significant at the 0.05 and 0.01 levels of probability, respectively.

+ HCN-p $=$ hydrocyanic acid potential. 
weight with each of the seedling height and weight traits, as well as between seed weight and total HCN per shoot. However, the association between seed weight and first-leaf $\mathrm{HCN}-\mathrm{p}$ was nonsignificant, and that between seed weight and shoot-remainder HCN$\mathrm{p}$, while statistically significant, was not close $(r=$ 0.12 ). The various seedling weight and height traits were significantly associated with each other and with seed weight, but none was closely associated with the HCN-p traits. The closest association was observed for the relationship of total shoot weight and shootremainder weight $(r=0.99)$. This result was not surprising inasmuch as the shoot remainder accounted for an average of $>80 \%$ of the total shoot weight. Total HCN per shoot was significantly correlated with each of the other measured traits, reflecting the dependence of total HCN on both the HCN-p and the quantity of shoot tissue.

When all entries were considered together (overall phenotypic values, Table 2) a strong relationship between seed weight and HCN-p was apparent. As pointed out by Lamb et al. (1987) and as verified by the data in Table 1 , this may be attributed to the fact that the sorghum entries had larger seeds and higher seedling $H C N-p$ values than the sudangrass entries. Also, seeds from the sudangrass $X$ sorghum crosses were smaller and seedlings were lower in $\mathrm{HCN}$-p than corresponding seeds and seedlings from sorghum $\times$ sudangrass hybrids. The mean comparisons discussed previously and the correlations within and across entries all verify the previous research of Lamb et al. (1987), which indicated that when seeds are identical with respect to genotype of both endosperm and embryo, seed weight has little if any effect on seedling HCN-p. Therefore, it is reasonable to infer than the seed-parent effect on seedling HCN-p in crosses of sorghum and sudangrass was not due primarily to the seed-parent effect on seed weight.

\section{Five-Day, Light- and Dark-Grown Seedlings}

Unfortunately, germination varied greatly in this test, and the number of available seedlings varied from 6 to 20 seedlings among the treatments. Also, although the spectral scans revealed a clear $330-\mathrm{nm}$ peak in each of the shoot extracts, the extracts of roots and seed remnants contained substances that interfered seriously with the reading at $330 \mathrm{~nm}$, the wave- length on which the spectrophotometric assay depends (Gorz et al., 1977). Despite these difficulties, several observations of interest resulted from this experiment.

1. The shoot portion accounted for $37 \pm 3 \%$ (mean \pm SE) of the fresh w and $82 \pm 1 \%$ of the $\mathrm{HCN}$ content of 5-d light-grown seedlings. Corresponding averages for etiolated seedlings were 61 $\pm 4 \%$ and $90 \pm 2 \%$. The observation that a preponderance of the seedling's HCN was present in the shoot agrees with the reports of Akazawa et al. (1960) and Loyd and Gray (1970).

2. The seed-parent effect on HCN-p, and differences in HCN-p, were less distinct for 5-d than for 7-d light-grown seedlings, and no seed-parent effect was observed in 5-d etiolated shoots. Respective $\mathrm{HCN}-\mathrm{p}$ values for 5-d light-grown shoots of 1904, BRedlan, $1904 \times$ BRedlan, and ARedlan $\times 1904$ were 481, 1362, 803, and 929 $\mathrm{mg} \mathrm{kg} \mathrm{k}^{-1}$ fresh wt. Corresponding values for $5-\mathrm{d}$ etiolated shoots were $293,374,358$, and $367 \mathrm{mg}$ $\mathrm{kg}^{-1}$ fresh wt. It appears that seedlings must be grown in the light for more than $5 \mathrm{~d}$ for differences in $\mathrm{HCN}$-p to be fully expressed.

3. Large/small seed weight ratios were $1.69 \pm 0.11$ for the light-grown seedlings and $1.68 \pm 0.08$ for the etiolated seedlings. Corresponding ratios for shoot $\mathrm{HCN}$-p were $1.08 \pm 0.06$ and $1.03 \pm 0.03$. As in the case of 7-d, soil-grown seedlings, seed size had little effect on shoot HCN-p.

\section{ACKNOWLEDGMENTS}

The excellent technical assistance of Carol A. Caha is gratefully acknowledged.

\section{REFERENCES}

Akazawa, T., P. Miljanich, and E.E. Conn. 1960. Studies on cyanogenic glycoside of Sorghum vulgare. Plant Physiol. 35:535-538. Falconer, D.S. 1981. Introduction to quantitative genetics. 2nd ed. Longman, Inc., New York.

Gorz, H.J., W.L. Haag, J.E. Specht, and F.A. Haskins. 1977. Assay of $p$-hydroxybenzaldehyde as a measure of hydrocyanic acid potential in sorghums. Crop Sci. 17:578-582.

Lamb, J.F.S., F.A. Haskins, H.J. Gorz, and K.P. Vogel. 1987. Inheritance of seedling hydrocyanic acid potential and seed weight in sorghum-sudangrass crosses. Crop Sci. 27:522-525.

Loyd, R.C., and E. Gray. 1970. Amount and distribution of hydrocyanic acid potential during the life cycle of plants of three sorghum cultivars. Agron. J. 62:394-397. 